\title{
A systematic review of professional supervision experiences and effects for allied health practitioners working in non-metropolitan health care settings
}

\author{
This article was published in the following Dove Press journal: \\ Journal of Multidisciplinary Healthcare \\ 26 August 2015 \\ Number of times this article has been viewed
}

\author{
Wendy H Ducat ${ }^{1,3}$ \\ Saravana Kumar ${ }^{2}$ \\ 'Cunningham Centre, Darling \\ Downs Hospital and Health Service, \\ Australia; ${ }^{2}$ School of Health Sciences, \\ International Centre for Allied Health \\ Evidence, Sansom Institute, University \\ of South Australia, Adelaide, SA, \\ Australia; ${ }^{3}$ Rural Clinical School, \\ School of Medicine, University of \\ Queensland, Brisbane, QLD, Australia
}

Correspondence: Wendy H Ducat, Queensland Centre for Mental Health Learning, The Park - Centre for Mental Health, Locked Bag 500, Archerfield, QLD 4I08 Australia Email wendy.ducat@health.qld.gov.au

\begin{abstract}
Introduction: In regional, rural, and remote settings, allied health professional supervision is one organizational mechanism designed to support and retain the workforce, provide clinical governance, and enhance service delivery. A systematic approach to evaluating the evidence of the experience and effects of professional supervision for non-metropolitan allied health practitioners and their service delivery is needed.
\end{abstract}

Methods: Studies investigating the experience and effects of professional supervision across 17 allied health disciplines in non-metropolitan health services were systematically searched for using standardized keywords across seven databases. The initial search identified 1,574 references. Of these studies, five met inclusion criteria and were subject to full methodological appraisal by both reviewers. Two studies were primarily qualitative with three studies primarily quantitative in their approach. Studies were appraised using McMaster critical appraisal tools and data were extracted and synthesized.

Results: Studies reported the context specific benefits and challenges of supervision in nonmetropolitan areas and the importance of supervision in enhancing satisfaction and support in these areas. Comparison of findings between metropolitan and non-metropolitan settings within one study suggested that allied health in non-metropolitan settings were more satisfied with supervision though less likely to access it and preferred supervision with other non-metropolitan practitioners over access to more experienced supervisors. One study in a regional health service identified the lack of an agreed upon definition and functions of supervision when supervisors from diverse allied health disciplines were surveyed. While methodologically weak, all studies reported positive perceptions of supervision across professionals, supervisors, and managers. This is in accordance with previous research in the wider supervision literature.

Discussion: Considering the large pool of studies retrieved for further investigation, few of these met inclusion criteria demonstrating the paucity of primary research in this area. Increased training, policies, and implementation frameworks to ensure the definition and functions of supervision are agreed upon across the allied health disciplines in non-metropolitan areas is needed. Furthermore, systematic evaluation of supervision implementation in non-metropolitan settings, investigation of the experience and effects of distance based supervision (versus faceto-face), and increased rigor in research studies investigating non-metropolitan allied health profession supervision is needed.

Keywords: clinical supervision, allied health, professional development

\section{Introduction}

Health practitioner professional supervision is one mechanism to support best practice that has been advocated and researched in recent years ${ }^{1,2}$ with policies being adopted 
across Australian public health settings nationwide. ${ }^{3,4}$ In regional, rural, and remote settings, henceforth referred to as "rural" or "non-metropolitan" settings, professional supervision is argued to be particularly important as a clinical governance and professional support strategy. This is due to well established recruitment and retention difficulties stemming from professional and geographical isolation; the complexity of the specialist generalist scope of practice faced by many rural practitioners; and high, intermittent workload demands with limited staffing, clinical, and operational resources available in these settings. ${ }^{5-7}$ While commentary on professional supervision is prolific, a systematic approach to assessing the state of the research is lacking in terms of both effectiveness of and perspectives on professional supervision. Moreover, previous studies have not focused on the diverse allied health disciplines specifically in the rural context with all its unique challenges.

\section{What is allied health professional supervision?}

Allied health professionals are not uniform in their access to, training in, expectations of and uptake of professional supervision, hereafter referred to as "supervision". ${ }^{8}$ However, in spite of differences between professions, available research shows that the aims, processes, and methods of supervision and in particularly what makes supervision effective - is more similar than different across professions. ${ }^{9}$

Supervision can be challenging to define, as many terms - including both professional and clinical supervision - are used interchangeably in the literature. ${ }^{10-12}$ Functions of supervision can be confusing with some health professionals perceiving supervision as a monitoring tool, thus blurring the functions of professional supervision with those of operational management. ${ }^{10,11}$ Supervision is multidimensional and includes normative, formative, and supportive activities. ${ }^{13}$ Activities including face-to-face sessions; on-site supervision incorporating goal setting; reflective practice; peer support and sharing good practice are commonly reported; with less commonly reported activities being off-site, telephone based sessions and those involving competency rating. ${ }^{12}$ In non-metropolitan areas, distance based supervision is common with some studies reporting equivalent satisfaction between distance based and face-to-face forms of supervision ${ }^{14}$ and others reporting less satisfaction with distance based supervision. ${ }^{12}$

In this systematic review, supervision is defined as a professional development and support tool designed to enhance service delivery, professional practice, and client outcomes and specifically as
[...] a working alliance between two or more professional members in which the aim is to achieve a range of goals that can be broadly categorised into themes relating to a) organisational/administrative functions, b) clinical practice, and c) provision of personal support to the employee. ${ }^{9}$

\section{What is known about the experiences and effects of supervision on professional practice and client outcomes?}

Previous systematic reviews within professional supervision and development literature have investigated supervision within the context of psychotherapists and counselors (where other allied health have been excluded), ${ }^{1,15}$ mental health nursing, ${ }^{16}$ medical education, ${ }^{17,18}$ and social work. ${ }^{19}$ These reviews generally report that supervision is perceived as positive however rigorous, primary research is needed. In terms of effective elements of supervision, a recent systematic review identified the following supervision strategies as effective: giving feedback to the therapist, use of audio/video recordings of supervision, use of multi-modal methods of supervision including reading, teaching, agenda, live demonstrations, use of an agenda, and a collaborative approach. ${ }^{1}$ Other studies have focused on individual satisfaction and relationship quality and have shown that clinicians find structured, regular participation where a supervisory relationship is marked by trust, empathy, and genuine regard - often referred to as a strong working alliance - as optimal supervision characteristics. ${ }^{9,15}$ The importance of supervisee driven support has also been demonstrated. For example, physiotherapists have reported benefits from selecting their own supervisor and the importance for both supervisee and supervisor to be clear about their purpose and links of supervision to professional development and reflective practice have been noted. ${ }^{11}$

Cochrane reviews have investigated related activities including educational outreach visits and continuing education demonstrating small to moderate effects of these activities on professional practice. ${ }^{20-22}$ There has also been some controversy with one study finding that supervision may affect client outcomes, ${ }^{23}$ while another randomized control trial in nursing failed to demonstrate a relationship between client outcomes and supervision. ${ }^{24}$ Most recently, a systematic review of clinical supervision for allied health professionals was published. ${ }^{10}$ The focus of this review was on definitional matters, the purpose, processes, and outcomes of supervision. The authors concluded that supervision was poorly defined, yet 
considered important and had perceived benefits across professional, organizational, and client outcomes within hospital and health services. The reviewers highlighted that the evidence was methodologically weak around effective processes and outcomes of supervision. ${ }^{10}$ Notably, this review did not focus on the research questions proposed in the present systematic review; namely regarding the experience and impact of professional supervision for allied health professionals specifically within the non-metropolitan contexts.

\section{Non-metropolitan health contexts}

Rural practitioners often face challenges of poor accessibility of resources, high levels of staff burnout, and professional isolation, and are more likely to engage in distance based forms of supervision. ${ }^{25}$ Literature to date has argued the need for supervision and professional support to be implemented in rural settings. For instance, one study investigated rural mental health professionals who reported inadequate supervision, feeling overwhelmed, and lower job satisfaction, perceived their service quality was lower and were susceptible to burnout. ${ }^{14}$ Non-metropolitan settings are different from urban contexts, and issues such as distance based supervision, professional isolation, and limited resources may all impact on the experience and effect of supervision for rural allied health professionals. This context is unique and has its own supervision challenges. Rural practitioners must troubleshoot geographical and professional isolation, focus on building up strategies to access resources and/or cope with limited resources, routinely manage technology such as telehealth, skype, web-based, online, distance based learning and supervision strategies and providing professional support for generalist practitioners with complex, extended scopes of practice. Clearly, these issues require their own attention in the literature due to the known inequity in non-metropolitan contexts compared with city based health services.

The aim of this comprehensive systematic review was to synthesize the current evidence base for both the experience and effects of professional supervision for allied health professionals working in non-metropolitan health settings. Specifically, the review questions were:

1. What are the experiences of professional supervision for allied health professionals working in non-metropolitan settings?

2. What are the effects of professional supervision on allied health practitioner practice and client outcomes in nonmetropolitan locations?

\section{Method}

This review included qualitative and quantitative primary research studies. Detailed inclusion and exclusion criteria are included in the Supplementary material.

\section{Search strategy}

Databases systematically searched included: CINAHL, PsycInfo, Medline, Clinical Evidence, Cochrane Library, Joanna Briggs Institute (JBI) Library of Systematic Reviews and EMBASE.

Initial search terms that were used were: (supervision or professional support or supervisee) and (allied health or mental health or psychol $\$$ or physiot $\$$ or speech therap\$ or speech patholo $\$$ or occupational therap $\$$ or social work $\$$ or or pharmac\$ or podiat\$ or nutrition $\$$ or diete $\$$ or dieti or radiog $\$$ or medical imaging or medical techn\$ or medical radiation\$ or audiolog $\$$ or counsel\$ or therap\$ or clinical measurement $\$$ or exercise physiology or orthoptic\$ or orthotic\$ or prosthetic\$) and (rural or regional or remote or nonmetropolitan).

In addition, pearling of the reference lists of eligible studies (secondary searching) was undertaken to identify any additional studies.

\section{Assessment of methodological quality}

An interdisciplinary allied health professional working group was established during the first 12 months of the review to develop the research question and parameters to the review.

Once criteria were established, the search was conducted by one reviewer (WHD) and retrieved items that met inclusion criteria were then assessed for methodological quality independently by two members of the research team (WHD, SK). Critical appraisal of the methodological quality of studies was undertaken using McMaster Critical Review Form - Qualitative Studies (Version 2.02) ${ }^{26}$ and McMaster Critical Review Form - Quantitative Studies. ${ }^{27}$ This tool was chosen for this systematic review as it was a published freely available tool, used extensively and caters for a range of research designs. Differences in judgment were resolved through discussion between the two reviewers. While a third reviewer would have become involved if necessary in order to reach consensus, this need did not arise.

\section{Selection of studies}

The initial search identified 1,574 studies pooled across all databases searched. Of these, duplicates were removed before articles were reviewed by the first author. Of the articles 
reviewed, 41 were selected for full text retrieval to further examine if they met the review inclusion criteria. Each of these studies was independently reviewed by two members of the review team to determine the degree to which they met the inclusion criteria.

Of the 41 studies selected for full text retrieval, five studies (Figure 1) were considered to have met the inclusion criteria and were subsequently critically appraised for methodological quality.

\section{Results}

Findings from this systematic review were summarized narratively, which was appropriate given the nature of the review questions, the studies included, and outcomes reported. The results from the systematic review are divided into two key sections, in accordance with the review questions.

Overall the five studies assessed for methodological quality consisted of two qualitative research studies; two cross-sectional quantitative research studies and one pre-post quantitative research study. No studies reported a sample from a remote area and no specific client outcomes were reported. Strong et $\mathrm{al}^{28}$ used focus group and interview methods and Dawson et $\mathrm{al}^{29}$ used focus group and a subsequent survey. Dawson et $\mathrm{al}^{30}$ used cross-sectional quantitative measures as did Kavanagh et al; ${ }^{31}$ while Xavier et $\mathrm{al}^{32}$ used a pre-post design for a distance based

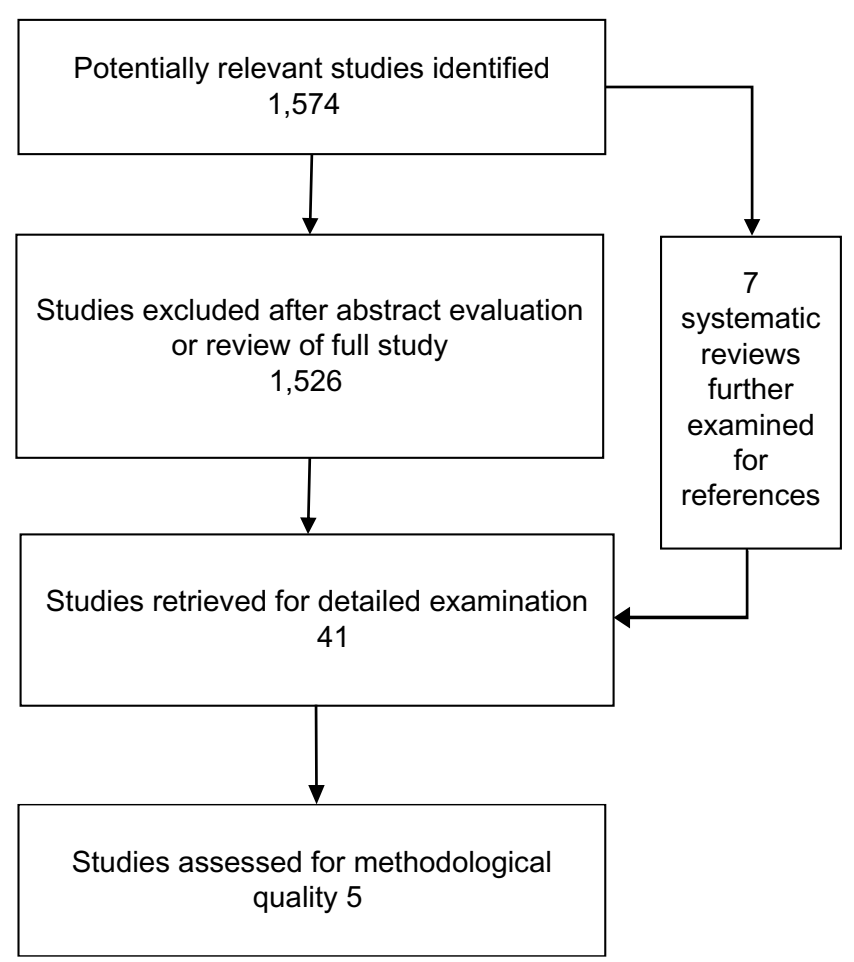

Figure I Flowchart detailing stages of systematic review. supervision intervention. Critical appraisals for qualitative studies are shown in Table 1 while quantitative studies are appraised in Table 2. Methodological quality and data extraction are reported under each research question. Finally, a narrative synthesis of key findings for each question is provided.

\section{Critical appraisal of qualitative research studies}

As shown in Table 1, all qualitative studies had a clear purpose, relevant literature review, purposeful sample selection, and overall trustworthiness. However, weakness with data collection was apparent; and the extent of sampling and informed consent were not reported in both studies. Strong et al's ${ }^{28}$ research was also lacking a clear study design and appropriate analysis. Dawson et al's ${ }^{29}$ study had a main methodological weakness in terms of the small sample size drawn from only one health service and inadequate investigation of any systematic differences between the nine disciplines sampled. Both studies contained appropriate conclusions given their study methods and findings and as such, findings from both were included in the review. Based on the paucity of studies retrieved the evidence in this area is weak.

\section{Critical appraisal of quantitative research studies}

As shown in Table 2, all quantitative studies had a clear purpose, relevant background literature review, with a sample size described in detail, and results that reported statistical significance. Weaknesses for all studies were a lack of justification of sample size and Xavier et $\mathrm{al}^{32}$ had particular weaknesses in terms of outcome measures, and lack of control for both contamination and co-intervention as part of their pre-post design. As Dawson et al's ${ }^{30}$ and Kavanagh et al's ${ }^{31}$ were cross-sectional studies; intervention rigor and clinical importance was not applicable. Response rates varied across studies including from $32 \%{ }^{30}$ to $72.5 \%{ }^{31}$ and $85 \% .^{32}$ As all three studies reported appropriate conclusions given their methodology and results; all were included in the review. Based on the small number of studies, each with at least one methodological weakness, the evidence in this area is weak.

Narrative synthesis of qualitative studies: what are the experiences of professional supervision for allied health professionals working in non-metropolitan settings?

Table 3 provides an overview of findings from the included studies. Strong et $\mathrm{al}^{28}$ conducted seven focus groups with 
Table I Qualitative studies: McMaster Critical Review Form Qualitative Studies (Version 2.0)*

\begin{tabular}{|c|c|c|}
\hline & $\begin{array}{l}\text { Strong } \\
\text { et } \mathrm{al}^{28}\end{array}$ & $\begin{array}{l}\text { Dawson } \\
\text { et } \mathbf{a l}^{29}\end{array}$ \\
\hline \multicolumn{3}{|l|}{ Study purpose } \\
\hline $\begin{array}{l}\text { Was the purpose and/or research question } \\
\text { stated clearly? }\end{array}$ & $\checkmark$ & $\checkmark$ \\
\hline \multicolumn{3}{|l|}{ Literature } \\
\hline Was relevant background literature reviewed? & $\checkmark$ & $\checkmark$ \\
\hline \multicolumn{3}{|l|}{ Study design } \\
\hline Was a theoretical perspective identified? & $x$ & $\checkmark$ \\
\hline \multicolumn{3}{|l|}{ Sampling } \\
\hline $\begin{array}{l}\text { Was the process of purposeful selection } \\
\text { described? }\end{array}$ & $\checkmark$ & $\checkmark$ \\
\hline $\begin{array}{l}\text { Was sampling done until redundancy in data } \\
\text { was reached? }\end{array}$ & NR & NR \\
\hline Was informed consent obtained? & NR & NR \\
\hline \multicolumn{3}{|l|}{ Data collection } \\
\hline Clear and complete description of site & $\checkmark$ & $\checkmark$ \\
\hline Clear and complete description of participants & $\checkmark$ & $\checkmark$ \\
\hline $\begin{array}{l}\text { Role of researcher and relationship with } \\
\text { participants }\end{array}$ & $x$ & $x$ \\
\hline $\begin{array}{l}\text { Identification of assumptions and biases of } \\
\text { researcher }\end{array}$ & $x$ & $x$ \\
\hline $\begin{array}{l}\text { Procedural rigor was used in data collection } \\
\text { strategies }\end{array}$ & $\checkmark$ & $\checkmark$ \\
\hline \multicolumn{3}{|l|}{ Data analysis } \\
\hline Data analyses were inductive & $\checkmark$ & NR \\
\hline $\begin{array}{l}\text { Findings were consistent with and reflective } \\
\text { of data? }\end{array}$ & $x$ & $\checkmark$ \\
\hline Decision trail developed? & $x$ & NR \\
\hline $\begin{array}{l}\text { Process of analyzing the data was described } \\
\text { adequately? }\end{array}$ & $\checkmark$ & $\checkmark$ \\
\hline $\begin{array}{l}\text { Did a meaningful picture of the phenomenon } \\
\text { under study emerge? }\end{array}$ & $x$ & $\checkmark$ \\
\hline \multicolumn{3}{|l|}{ Overall rigor } \\
\hline \multicolumn{3}{|l|}{$\begin{array}{l}\text { Was there evidence of the four components } \\
\text { of trustworthiness? }\end{array}$} \\
\hline Credibility & $\checkmark$ & $\checkmark$ \\
\hline Transferability & $\checkmark$ & $\checkmark$ \\
\hline Dependability & $\checkmark$ & $\checkmark$ \\
\hline Confirmability & $x$ & $\checkmark$ \\
\hline \multicolumn{3}{|l|}{ Study conclusions and implications } \\
\hline $\begin{array}{l}\text { Conclusions were appropriate given the study } \\
\text { findings? }\end{array}$ & $\checkmark$ & $\checkmark$ \\
\hline $\begin{array}{l}\text { The findings contributed to theory } \\
\text { development and future practice/research }\end{array}$ & $\checkmark$ & $\checkmark$ \\
\hline
\end{tabular}

Notes: *Only the key questions on the left-hand side have been reported, without the question regarding study design and methods used as this is covered in data extraction; $\checkmark$ refers to criteria met within study and $x$ refers to criteria not met. Abbreviation: NR, not reported.

psychologists, social workers, occupational therapists, and speech pathologists from Queensland with $31 \%$ of the sample working in rural areas. In addition service managers were interviewed by telephone. Both service managers and allied health clinicians reported value in supervision, particularly for ensuring staff competence and best practice client outcomes. These authors highlighted that accessibility
Table 2 Quantitative studies: McMaster Critical Review Form Quantitative Studies*

\begin{tabular}{|c|c|c|c|}
\hline & $\begin{array}{l}\text { Dawson } \\
\text { et } \mathbf{a l}^{30}\end{array}$ & $\begin{array}{l}\text { Kavanagh } \\
\text { et } \mathbf{a l}^{31}\end{array}$ & $\begin{array}{l}\text { Xavier } \\
\text { et } \mathrm{al}^{32}\end{array}$ \\
\hline \multicolumn{4}{|l|}{ Study purpose } \\
\hline Was the purpose clearly stated? & $\checkmark$ & $\checkmark$ & $\checkmark$ \\
\hline \multicolumn{4}{|l|}{ Literature } \\
\hline Was relevant background & $\checkmark$ & $\checkmark$ & $\checkmark$ \\
\hline \multicolumn{4}{|l|}{ literature reviewed? } \\
\hline \multicolumn{4}{|l|}{ Sample } \\
\hline $\begin{array}{l}\text { Was the sample described in } \\
\text { detail? }\end{array}$ & $\checkmark$ & $\checkmark$ & $\checkmark$ \\
\hline Was sample size justified? & $x$ & $x$ & $x$ \\
\hline \multicolumn{4}{|l|}{ Outcomes } \\
\hline $\begin{array}{l}\text { Were the outcome measures } \\
\text { reliable? }\end{array}$ & NR & $\checkmark$ & $x$ \\
\hline $\begin{array}{l}\text { Were the outcome measures } \\
\text { valid? }\end{array}$ & $\checkmark$ & $\checkmark$ & $x$ \\
\hline \multicolumn{4}{|l|}{ Intervention } \\
\hline Intervention was described in detail? & NA & NA & $\checkmark$ \\
\hline Contamination was avoided? & NA & NA & $x$ \\
\hline Co-intervention was avoided? & NA & NA & $x$ \\
\hline \multicolumn{4}{|l|}{ Results } \\
\hline $\begin{array}{l}\text { Results were reported in terms } \\
\text { of statistical significance? }\end{array}$ & $\checkmark$ & $\checkmark$ & $\checkmark$ \\
\hline $\begin{array}{l}\text { Were the analysis method(s) } \\
\text { appropriate? }\end{array}$ & \multicolumn{2}{|c|}{ appropriate? } & NR \\
\hline Clinical importance was reported? & NA & NA & $x$ \\
\hline Drop-outs were reported? & NA & NA & $\checkmark$ \\
\hline \multicolumn{4}{|l|}{ Conclusions and implications } \\
\hline $\begin{array}{l}\text { Conclusions were appropriate given } \\
\text { study methods and } \\
\text { results }\end{array}$ & $\checkmark$ & $\checkmark$ & $\checkmark$ \\
\hline
\end{tabular}

Notes: *Only the key questions on the left-hand side have been reported, without the question regarding study design as this is covered in data extraction; $\checkmark$ refers to criteria met within study and $x$ refers to criteria not met.

Abbreviations: NR, not reported; NA, not applicable.

of supervision was an issue for rural compared with non-rural respondents and that rural respondents reported supervision was more valuable in terms of job satisfaction and professional support than for non-rural counterparts. Variability in supervision practice, an ad hoc approach, and the need for training in supervision were all highlighted as warranting further attention. The authors highlighted that articulation of policy and available resources to support supervision practice were needed for improvements in supervision practice to occur.

In Dawson et al's study ${ }^{29}$ almost 10 years later, the experience of supervision was explored from the supervisors' perspective in one small regional health service in Victoria, Australia and sampled a larger mix of allied health professions (nine in total). Similar to the earlier qualitative study, organizational issues in the effective implementa- 


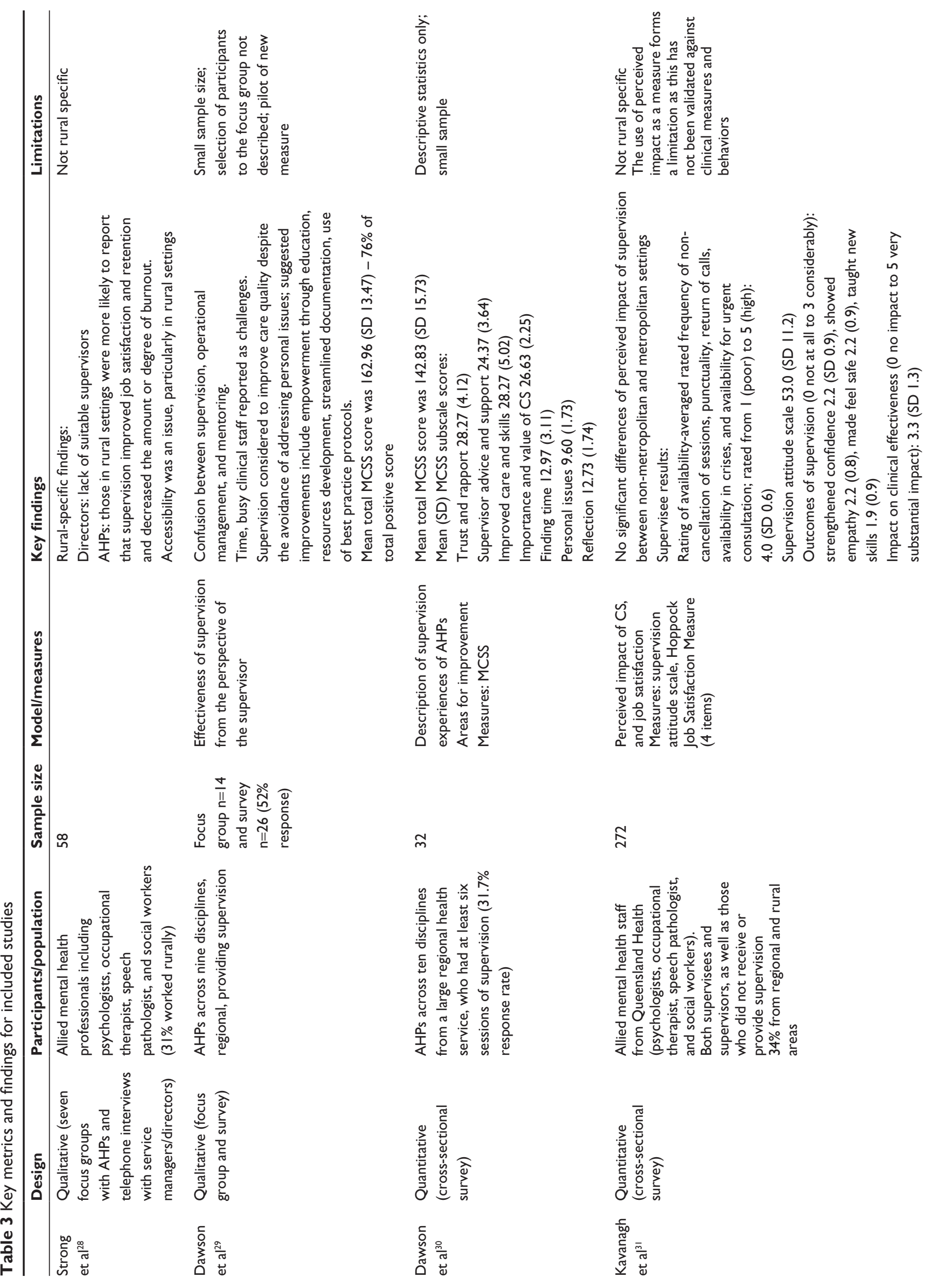


tion of supervision were raised. Suggested improvements around organizational support for supervision were provided including the use of protected time of supervision and the role of providing critical feedback to support the normative aspects of supervision were highlighted in this study. One clear finding was the confusion over the differentiation of supervision from operational management with the respondents' split almost 50/50 on whether operational managers could effectively provide supervision. In addition there was disagreement over functions of supervision including the provision of critical feedback and whether supervision was a performance appraisal tool. Supervision was perceived as beneficial by the supervisors in this study and assisted with finding time for themselves and reflection on practice. Barriers including time and clinical load were reported, dual relationships when a practitioner was asked to supervise a colleague who was a friend, increase in documentation, and lack of choice of supervisor. Recommendations for improvement within this health setting included the need for more time, resources, consistency, structure, and feedback in regards to the supervision process.

\section{Narrative synthesis of quantitative studies: what are the effects of professional supervision on allied health practitioner practice and client outcomes in non-metropolitan locations?}

As shown in Table 3, Kavanagh et $\mathrm{al}^{31}$ used perceived impact as a measure of supervision effectiveness in a state-wide survey of Queensland allied mental health professionals with $34 \%$ from regional and rural areas of the state. The authors developed a new measure of supervision impact, however, while reliability data were reported, no information about validity was reported. Results indicate that both supervisees and supervisors reported beneficial perceived impacts of supervision. Discipline specific supervision was perceived as impactful. Organizational support and protected time for supervision were called for as well as supervision training. The impact of supervision was not significantly different based on location (regional and rural versus metropolitan).

Xavier et $\mathrm{al}^{32}$ reported on a pre-post study investigating the effects of supervision and education delivered via videoconference and teleconference to oncology allied health professionals from psychology and social work backgrounds (61\% rural sample). These authors found that supervisees were satisfied with teleconference format of supervision and self-reported improvements in confidence, knowledge, and skill around 
managing psychological distress in oncology patients. The authors reported one rural-specific difference, namely that rural clinicians preferred to be part of supervision/education sessions with other rural clinicians if they had the choice between this and being "matched" based on level of experience. Dawson et $\mathrm{al}^{30}$ validated the Manchester Clinical Supervision Scale with allied health in one regional health service in Victoria, Australia. Findings were largely descriptive, although it demonstrated that allied health professionals viewed their supervision arrangements as effective (based on normative data derived from nursing populations). As with Dawson et al's ${ }^{29}$ study with supervisors, supervisees reported improvements in being able to address personal issues that interfere with work performance and finding protected time for supervision. A small regional health service and poor response rate $(31.7 \%)$ limits the generalizability of these findings.

\section{Discussion}

Overall, the findings from this systematic review indicate that there was general consensus on the beneficial aspects of supervision and hence the need for organizations to promote effective supervision with quarantined time dedicated for this purpose. ${ }^{28-32}$ While there was general consensus on the importance of supervision, the literature also highlighted areas for improvement including improving training to support supervision ${ }^{28,29,31}$ and the use of innovative technologies (such as videoconference/teleconference), which are increasingly acceptable mediums for supervision. Research recognizes that non-metropolitan contexts are unique, and hence supervision can play an important role in supporting health professionals located in these areas. Given the sparse resources available, rural supervisees seem to have higher difficulties accessing supervision but reported more value on supervision as a professional support tool and as enhancing job satisfaction compared with their metropolitan counterparts. ${ }^{28}$ Further highlighting the uniqueness of nonmetropolitan contexts, and hence their shared values and perspectives, clinicians from these settings preferred to be part of supervision/education sessions with other rural clinicians as opposed to being matched based on level of experience compared with their metropolitan counterparts. ${ }^{32}$

One limitation of this narrative synthesis is that it is informed by only a small number of studies. Hundreds of studies of supervision $(1,574)$ were retrieved across multiple literature searches and of these, only five studies met the inclusion criteria. None of these studies specifically investigated the contextual variables unique to non-metropolitan health services, with three having a mixed sample; and two studies conducted in a small regional health service in Australia. This highlights the current knowledge gap in this area. Of the studies retrieved, all were subject to methodological weakness. Despite these limitations, there is an emerging body of evidence on the importance of supervision for allied health professions in non-metropolitan settings.

Moving forward clear articulation of the purpose and benefits of supervision through policy, training, and ongoing implementation support is required. In accordance with the broader literature, ${ }^{10-12}$ there is ongoing confusion and variable perceptions of what supervision is, how it is communicated within the organization, functions and benefits, particularly when supervision is studied across multiple allied health professions. This results in variability and inconsistency in access to or experience of supervision for allied health professionals. This is an important finding demonstrating that further work by organizations on what supervision is in the context of multiple health disciplines, continues to be needed. Continued efforts to implement and evaluate supervision frameworks, including policies, training, guidelines, and other forms of organizational support are important. There is a need for evaluation of systematic efforts to promote effective supervision in non-metropolitan contexts. Despite ongoing calls for supervision in this context, ${ }^{5-8}$ there continues to persist knowledge and practice gaps. The literature included in this review highlights that supervision appears to be important in this setting, access to effective supervision needs to be improved; and non-metropolitan supervisors are important for rural supervision arrangements. The critical functions of supervision in this context may be more highly linked to professional support and job satisfaction than for metropolitan counterparts. Effective and consistent translation of these findings into health care settings is needed.

Ongoing systematic evaluation of distance based supervision to ensure best practice in supervision arrangements across distance is required. This is an emerging area within supervision and the results of the pilot study included in this review showed that videoconferencing is viable and is associated with beneficial outcomes for distance based supervisees. However, for these innovative technologies to be embedded in practice, a number of barriers, such as lack of access to and effective use of technology, lack of dedicated time for supervision when competing with clinical priorities, and lack of organizational support need to be addressed.

Finally, given that there is consistent evidence that supervision is of value within non-metropolitan settings, further methodologically rigorous studies need to be designed and conducted to understand the specific effects of elements of 
supervision versus the non-specific effects that have dominated the literature to date. The consistency of positive findings in the supervision literature seems to support the fundamental value of this activity, however, also highlights the complexity of this area and multiple definitional, process, and outcome variables that are not clear. Rigorous, high quality research on the effectiveness of supervision practices and contexts, particularly within the allied health professions, is required. In particular, key implementation (process) variables need to be appropriately defined and investigated with impacts on professional practice and patient outcome appropriately assessed. By doing so, an enhanced, evidence based understanding and application of effective supervision practices for allied health professionals in rural contexts can be developed.

\section{Acknowledgments}

The authors would like to thank the Allied Health Education and Training team at the Cunningham Centre, Darling Downs Hospital and Health Service and particularly Dr Ans Van Erp, Ms LuJuana Abernathy, Ms Vanessa Burge, and Ms Priya Martin who provided ongoing support throughout preparation of this review. Dr Maxine O'Brien, Dr Susanne Pearce, Dr Melissa Kaltner, and Mr Daniel McDonald are also acknowledged for their expert advice and support during the preparation of this review.

\section{Disclosure}

There is no conflict of interest to report.

\section{References}

1. Milne D, Reiser R, Aylott H, Dunkerley C, Fitzpatrick H, Wharton S. The systematic review as an empirical approach to improving CBT supervision. International Journal of Cognitive Therapy. 2010;3(3):278-294.

2. White E, Winstanley J. Does clinical supervision lead to better patient outcomes in mental health nursing? Nurs Times. 2010;106(16):16-18.

3. Fitzpatrick S, Smith M, Wilding C. Quality allied health clinical supervision policy in Australia: A literature review. Aust Health Rev. 2012; 36(4):461-465.

4. Hall F, Bell K. Professional support framework: Improving access to professional support for professionals. Aust Health Rev. 2013;37(5):560-565.

5. Steenbergen K, Mackenzie L. Professional support in rural New South Wales: perceptions of new graduate occupational therapists. Aust J Rural Health. 2004;12(4):160-165.

6. Struber JC. Recruiting and retaining Allied Health Professionals in rural Australia: why is it so difficult? Internet Journal of Allied Health Sciences and Practice. 2004;2(2):1-13.

7. Schoo AM, Stagnitti KE, Mercer C, Dunbar J. A conceptual model for recruitment and retention: allied health workforce enhancement in Western Victoria, Australia. Rural Remote Health. 2005;5(4):477.

8. Keane S, Smith TN, Lincoln M, Wagner SR, Lowe SE. The rural allied health workforce study (RAHWS): background, rationale and questionnaire development. Rural Remote Health. 2008;8(4):1132.

9. Spence SH, Wilson J, Kavanagh D, Strong J, Worrall L. Clinical supervision in four mental health professions: A review of the evidence. Behaviour Change. 2001;18(3):135-155.
10. Dawson M, Phillips B, Leggat S. Clinical Supervision for Allied Health Professionals: A Systematic Review. J Allied Health. 2013; 42(2):65-73.

11. Hall T, Cox D. Clinical supervision. An appropriate term for physiotherapists? Learning in Health and Social Care. 2009;8(4):282-291.

12. Cox DL, Araoz G. The experience of therapy supervision within a UK multi-centre randomized controlled trial. Learning in Health and Social Care. 2009;8(4):301-314.

13. Proctor B. Supervision: a co-operative exercise in accountability. In: Marken M, Payne M, editors. Enabling and ensuring. Leicester: Leicester National Youth Bureau and Council for Education and Training in Youth and Community Work; 1986:21-23.

14. Reese RJ, Aldarondo F, Anderson CR, Lee S-J, Miller TW, Burton D. Telehealth in clinical supervision: a comparison of supervision formats. J Telemed Telecare. 2009;15(7):356-361.

15. Wheeler S, Richards K. The impact of clinical supervision on counsellors and therapists, their practice and their clients. A systematic review of the literature. Counselling and Psychotherapy Research:Linking. 2007;7(1):54-65.

16. Buus N, Gonge H. Empirical studies of clinical supervision in psychiatric nursing: A systematic literature review and methodological critique. Int J Ment Health Nurs. 2009;18(4):250-264.

17. Kilminster SM, Jolly BC. Effective supervision in clinical practice settings: a literature review. Med Educ. 2000;34(10):827-840.

18. Farnan JM, Petty LA, Georgitis E, et al. A systematic review: the effect of clinical supervision on patient and residency education outcomes. Acad Med. 2012;87(4):428-442.

19. Bogo M, McKnight K. Clinical Supervision in Social Work: A Review of the Research Literature. The Clinical Supervisor 2005; 24(1-2):49-67.

20. Forsetlund L, Bjorndal A, Rashidian A, et al. Continuing education meetings and workshops: effects on professional practice and health care outcomes. Cochrane Database Syst Rev. 2009;(2):CD003030.

21. Thomson O'Brien MA, Freemantle N, Oxman AD, Wolf F, Davis DA, Herrin J. Continuing education meetings and workshops: effects on professional practice and health care outcomes. Cochrane Database Syst Rev. 2001;(2):CD003030.

22. Thomson O'Brien MA, Rogers S, Jamtvedt G, Oxman AD, Odgaard-Jensen J, Kristoffersen DT, et al. Educational outreach visits: effects on professional practice and health care outcomes. Cochrane Database Syst Rev. 2007;(4):CD000409.

23. Steinhelber J, Patterson V, Cliffe K, LeGoullon M. An investigation of some relationships between psychotherapy supervision and patient change. J Clin Psychol. 1984;40(6):1346-1353.

24. WhiteE, Winstanley J. A randomised controlled trial of clinical supervision: Selected findings from a novel Australian attempt to establish the evidence base for causal relationships with quality of care and patient outcomes, as an informed contribution to mental health nursing practice development. Journal of Research in Nursing. 2010;15(2):151-167.

25. Rourke J. WHO Recommendations to improve retention of rural and remote health workers - important for all countries. Rural Remote Health. 2010;10(4):1654.

26. McMaster University. Letts L, Wilkins S, Law M, Stewart D, Bosch J, Westmorland M. Critical Review Form - Qualitative Studies (Version 2.0). Ontario: McMaster University; 2007. Available from: https://www.canchild.ca/en/canchildresources/resources/qualform.pdf. Accessed June 30, 2015.

27. McMaster University. Law M, Stewart D, Pollock N, Letts L, Bosch J, Westmorland M. Critical Review Form-Quantitative Studies. Ontario: McMaster University; 1998. Available from: https://www.canchild.ca/en/ canchildresources/resources/quantguide.pdf. Accessed June 30, 2015.

28. Strong J, Kavanagh D, Wilson J, Spence SH, Worrall L, Crow N. Supervision practice for allied health professionals within a large mental health service: Exploring the phenomenon. The Clinical Supervisor. 2003;22(1):191-210.

29. Dawson M, Phillips B, Leggat SG. Effective clinical supervision for regional allied health professionals - the supervisor's perspective. Aust Health Rev. 2013;37(2):262-267. 
30. Dawson M, Phillips B, Leggat SG. Effective clinical supervision for regional allied health professionals - the supervisee's perspective. Aust Health Rev. 2012;36(1):92-97.

31. Kavanagh DJ, Spence SH, Strong J, Wilson J, Sturk H, Crow N. Supervision practices in allied mental health: relationships of supervision characteristics to perceived impact and job satisfaction. Ment Health Serv Res. 2003;5(4):187-195.
32. Xavier K, Shepherd L, Goldstein D. Clinical supervision and education via videoconference: a feasibility project. J Telemed Telecare. 2007; 13(4):206-209. 


\section{Supplementary materials \\ Inclusion criteria \\ Types of studies}

This review included both qualitative studies exploring participants' perspectives on participation in supervision; and quantitative evidence including the objective measurement of rates of participation and effectiveness of supervision. Only primary research published in a peer-reviewed journal was included. Unpublished reports, dissertations, and conference presentations/papers were not included in this review. To ensure only contemporary primary research was included that related to current regional, rural, and remote contexts, the search was limited to studies published between January 2000 and July 2013.

\section{Types of participants}

The definition of allied health professions varies across health settings, nationally and internationally. This review focused on all allied health professionals as defined within Queensland Health Hospital and Health Services, Australia including, audiology, clinical measurement sciences, dietetics and nutrition, exercise physiology, medical radiations professions, occupational therapy, orthoptics, pharmacy, physiotherapy, podiatry, prosthetics and orthotics, physiotherapy, podiatry, psychology, social work, and speech pathology in all health care settings (private practice, community health, and hospital settings) working in regional, rural, and remote locations.

Defining what constitutes regional, rural, and remote (ie, non-metropolitan) within a worldwide context is difficult, hence for this review regional, rural, and remote practice was defined as working in geographic or professional isolation within a service self-identified as regional, rural, or remote (ie, non-metropolitan). Studies investigating allied health supervision in both metropolitan and non-metropolitan areas were included as long as there were results specifically relating to the non-metropolitan setting.

\section{Phenomena of interest/types of intervention(s)}

The focus of both qualitative and quantitative components of the review was on professional supervision. The review included all styles of supervision such as face-to-face, telephone, videoconference or online to both individuals and groups. For this review supervision was defined as:

[...] a working alliance between two or more professional members in which the aim is to achieve a range of goals that can be broadly categorised into themes relating to (a) organisational/administrative functions, (b) clinical practice, and (c) provision of personal support to the employee. ${ }^{1}$

\section{Exclusion criteria}

- Students not employed as an allied health professional (eg, allied health students on clinical placements were excluded);

- medical clinicians;

- nursing clinicians;

- health workers (other than allied health);

- Child welfare workers or counselors (other than allied health);

- allied health assistants;

- operational or line management, operational supervision other than the definitions provided earlier;

- journal club (without other supervisory activities);

- professional development, educational meetings, training activities, or in-services (without other components of supervision as defined earlier);

- audit;

- mentoring;

- feedback only (without other components of supervision).

\section{Reference}

1. Spence SH, Wilson J, Kavanagh D, Strong J, Worrall L. Clinical supervision in four mental health professions: A review of the evidence. Behaviour Change. 2001;18(3):135-155.

\section{Publish your work in this journal}

The Journal of Multidisciplinary Healthcare is an international, peerreviewed open-access journal that aims to represent and publish research in healthcare areas delivered by practitioners of different disciplines. This includes studies and reviews conducted by multidisciplinary teams as well as research which evaluates the results or conduct of such teams or

\section{Dovepress}

healthcare processes in general. The journal covers a wide range of areas and welcomes submissions from practitioners at all levels, from all over the world. The manuscript management system is completely online and includes a very quick and fair peer-review system. Visit http://www.dovepress.com/testimonials.php to read real quotes from published authors. 